\title{
Saprotrophic soil fungi to improve phosphorus solubilisation and release: In vitro abilities of several species
}

\author{
Andrea Ceci, Flavia Pinzari, Fabiana Russo, Oriana Maggi, \\ Anna Maria Persiani
}

Published online: 20 November 2017

\begin{abstract}
Modern agriculture is dependent on phosphate rock (PR), which is a nonrenewable resource. Improvement of phosphorus $(\mathrm{P})$ availability for crops in agricultural soils represents a key strategy to slow down the depletion of PR. The aim of this study was to identify potential $P$ biofertilisers among saprotrophic fungal species. We tested 30 fungal strains belonging to 28 taxa (4 Zygomycota and 24 Ascomycota) and with different life strategies. The study showed that many saprotrophic fungi have the ability to mobilise $\mathrm{P}$ from insoluble forms according to a variety of mechanisms. Our results expand the pool of $\mathrm{P}$ solubilising fungal species, also suggesting a new solubilisation index and shedding light on parameters that could be basic in the selection of efficient soil P-biofertilisers fungi. Rhizopus stolonifer var. stolonifer, Aspergillus niger and Alternaria alternata were found to be the best performing strains in terms of amounts of TCP solubilisation.
\end{abstract}

Keywords Biofertilisers - Biomineralisation ·

Indices P solubilisation - Phosphorus .

Soil saprotrophic fungi $\cdot$ Tricalcium phosphate

\section{INTRODUCTION}

Global climate change and fast increase in the world population require a more efficient agriculture and food production. Modern agriculture and intensive crop production increase the demand for fertilisers (Rouached 2016). The world demand for phosphatic fertilisers is forecasted to grow annually by $2.2 \%$ between 2014 and 2018 (FAO 2015). However, modern agriculture is dependent from phosphate rock (PR), which is a non-renewable resource. In fact, current global reserves may be depleted in 50-100 years (Gunther 2005) and the fertilisers industry recognises that the quality of reserves is declining while the cost of extraction, processing and shipping is increasing (Cordell et al. 2009). One recent European Union's report underlined the future phosphorus (P) limitation as one of the main reasons for the vulnerability of the European food system (Rouached 2016). Responses should include a more efficient production and use of $\mathrm{P}$ resources, as well as a greater awareness to avoid over-fertilisation with resulting environmental problems (e.g. eutrophication). A more integrated and effective approach to manage the P cycle is needed (Cordell et al. 2009). In this context, biofertilisation could have a positive role since it is based on the use of natural inputs including decaying remains of organic matter, animal manure, and the use of microorganisms such as fungi and bacteria (Carvajal-Muñoz and Carmona-Garcia 2012). A biofertiliser is a substance which contains living microorganisms which, when applied to soil, promote plants' growth by increasing the supply or availability of primary nutrients.

The use of phosphate-solubilising microorganisms (bacteria and fungi) that break down inorganic soil phosphates to simpler forms thus enabling uptake by plants has been widely suggested (Saxena et al. 2014; Malusà et al. 2016). This approach has the potential not only to reduce the use of PR and its derivatives, but also improve the solubilisation of insoluble $\mathrm{P}$ minerals in a cheap, environmentally friendly and sustainable way, basically promoting plant growth by optimisation of stable soil $\mathrm{P}$ sources use. Fungi, in particular, resulted to be more efficient than bacteria in $\mathrm{P}$ solubilisation, on both solid agar and in liquid cultures (Kucey 1983; Halder et al. 1990; Saxena et al. 2014). Among the fungi, mycorrhizas are already exploited to improve $\mathrm{P}$ availability to plants as plant growth-promoting microorganisms (PGPM) (Owen et al. 2015). 
Arbuscular mycorrhizal (AM) fungi are vital components of nearly all terrestrial ecosystems, forming mutualistic symbioses with the roots of around $80 \%$ of vascular plants, thereby increasing phosphate uptake and growth. The mycorrhizas greatly increase the absorptive area of a plant, acting as extensions to the root system.

Mycorrhizas are vital in gathering $\mathrm{P}$ in uncultivated soils but in agricultural realities not all the crops can form mycorrhizas, and despite of mycorrhization in some soils, optimal $\mathrm{P}$ quantity for sustaining productivity may not be found (Oehl et al. 2004). Moreover, phosphorus-rich fertilisers suppress the mycorrhiza formation. Studies in which the soil $\mathrm{P}$ has been labelled with radioactive ${ }^{32} \mathrm{P}$ indicated that both mycorrhizal and non-mycorrhizal plants utilised the similarly labelled $\mathrm{P}$ sources in soil (Bolan 1991). In many soils the main issue is the solubility of $P$ and its slow release in the right forms to be absorbed by the plants' roots.

Studies on the potential of soil saprotrophic fungi in $\mathrm{P}$ release from insoluble forms in soil are still scarce and only a few species have been studied, with a predominance of Aspergillus and Penicillium species. Aspergillus niger is a very efficient organic acid producing fungus and has been described in many studies as a strong $\mathrm{P}$ solubiliser (Pradhan and Sukla 2006; El-Azouni 2008; Bojinova et al. 2008; Pinzari et al. 2012). Other fungal genera successfully tested by some authors for their phosphate solubilisation ability are Trichoderma, Mucor, Candida, Discosia, Eupenicillium, Gliocladium and some species of yeasts (Rosling et al. 2007; Jain et al. 2012; Saxena et al. 2014). The mechanisms of PR solubilisation by saprotrophic soil fungi can be very diversified between species, for example entailing the production of different combinations of organic acids such as oxalic and citric, in order to attack the PR structure and increase its solubility. The potential of some species to be used as P-solubilisation helpers in poor or highly exploited soils is still untapped. On the other side, fungi can also mediate the formation of new secondary minerals of $\mathrm{P}$, reducing the $\mathrm{P}$ loss from soil because of surface run off (Burford et al. 2003; Fomina et al. 2005).

The use of $\mathrm{P}$ solubilising fungi in agriculture could be addressed also to the treatment of agro-industrial wastes and the production of organo-mineral fertilisers, where mineral $\mathrm{P}$ is partially immobilised into biomass and could be slowly released in soil. In many countries exhausted fungal biomasses are used as fertilisers. The Italian law, for example, allows the use of exhausted fungal material as $\mathrm{N}-\mathrm{P}$ fertiliser if it contains at least $1 \% \mathrm{P}_{2} \mathrm{O}_{5}$ (Italian legislative decree 29th April 2010, n. 75 and its modifications). Therefore, the selection of fungi capable of solubilising or storing $\mathrm{P}$ could have an application in the vast field of fertiliser production and improvement.
The aim of this study was to select strains that, when applied to agricultural soil, could promote the growth of plants by improving the supply or availability of $\mathrm{P}$. We tested 30 fungal strains belonging to 28 taxa (4 Zygomycota and 24 Ascomycota) with different life strategies on Pikovskaya's medium containing $5 \%$ tricalcium phosphate (TCP). The evaluation of secondary minerals precipitation by fungi and the strategies of $\mathrm{P}$ uptake by fungal biomasses were investigated at a microscale level, using Scanning electron microscopy (SEM) coupled with energy-dispersive X-ray spectroscopy (EDS). SEM has been used extensively for the visualisation of fungi in association with minerals (Fomina et al. 2005; Burford et al. 2006; Rosling et al. 2007) because it can provide spatial information at the micrometer to sub-micrometer scales and when used with EDS it can reveal high-resolution elemental compositional measurements. The presence of secondary minerals formation in the floating fungal mycelium was documented and their elemental composition evaluated by EDS.

\section{MATERIALS AND METHODS}

\section{Solubilisation test in PVK agar medium}

Thirty strains of saprotrophic fungi were tested for their $\mathrm{P}$ solubilisation and uptake ability. They are currently preserved at the culture collection of the Fungal Biodiversity Lab (FBL) (Sapienza, University of Rome) (Table 1). The selected strains were representative taxa of different phyla. The strains were isolated in previous studies mostly from soil and from different geographical areas, such as Mediterranean maquis soils (e.g. Minimedusa polyspora) and tropical forest soils (e.g. Heterocephalum taiense) (Persiani and Maggi 1986; Pinzari et al. 2014). Many of the isolates belong to either genera or species known for their ability in mineral $\mathrm{P}$ solubilisation. This is the case for Aspergillus, Rhizopus, Alternaria, and Penicillium. In particular, A. niger was tested as a positive control, to be compared with the other species. The selected strains possess different physiological and metabolic features. Some of them can play several ecological functions in ecosystems. For instance, Trichoderma harzianum is reported to have biocontrol properties, which could be a further element of interest (Vassilev et al. 2006).

Among the tested strains, a few of them, like A. niger, Cladosporium sp. and A. alternata are common soil saprotrophic species that in some conditions can behave as pathogens for humans and/or plants. These were chosen since their r-selected life-style characterizes them as fastgrowing species with high potential for biomass production. Exhausted and sterilised fungal biomasses containing 
Table 1 List of the 30 fungal strains tested in solid culture on Pikovskaya's medium containing 5\% insoluble tricalcium phosphate as only $\mathrm{P}$ source. From left to right in columns: growth diameter $(\mathrm{mm})$ of the fungal colony, halo zone $(\mathrm{mm})$ measured under the colony after the removal of the cellophane membrane, fungal biomass expressed as dry weight ( $\mathrm{g}$ ), average $\mathrm{pH}$ of the Pikovskaya's medium after fungal growth. The values are reported as averages \pm Standard deviation out of three biological replicas. Within each replicas (i.e. plate/colony) at least 10 measures were effected to obtain a single average value in the case of diametrical data because of the variability of the shape that fungal colonies can assume according to the species and growth peculiarities

Fungal strains Growth Halo zone Dry weight $\mathrm{pH}$

Alternaria alternata (Fr.) Keissl. FBL 508

Alternaria sp. FBL 507

Anamorphic fungus FBL 165

Arthrinium arundinis (Corda) Dyko \& B. Sutton FBL 266

Aspergillus niger Tiegh. FBL 453

Aspergillus sp. FBL 253

Cadophora fastigiata Lagerb. \& Melin FBL 557

Cladosporium sp. FBL 513

Cladosporium tenellum K. Schub, Zalar, Crous \& U. Braun FBL 505

Engyodontium album (Limber) de Hoog FBL 458

Epicoccum nigrum Link FBL 181

Heterocephalum taiense Persiani \& Maggi FBL 249

Microdiplodia sp. FBL 512

Minimedusa polyspora 7 (Hotson) Weresub \& P. M. LeClair FBL 503

Minimedusa polyspora 5b (Hotson) Weresub \& P. M. LeClair FBL 514

Minimedusa polyspora 5a (Hotson) Weresub \& P. M. LeClair FBL 502

Mortierella globalpina W. Gams \& Veenb.-Rijks FBL 74

Myrothecium cinctum (= Striaticonidium cinctum (Corda) L. Lombard \& Crous) $41.7 \pm 2.9$ FBL 383

Myrothecium verrucaria (= Albifimbria verrucaria (Alb. \& Schwein.) L. Lombard $24.0 \pm 1.0$ \& Crous) FBL 385

Oidiodendron sp. FBL 319

Paecilomyces lilacinus (= Purpureocillium lilacinum (Thom) Luangsa-ard, Houbraken, Hywel-Jones \& Samson) FBL 320

Paecilomyces marquandii (= Metarhizium marquandii (Massee) Kepler, S.

A. Rehner \& Humber) FBL 321

Paecilomyces variotii Bainier FBL 213

Penicillium griseofulvum Dierckx FBL 500

Phycomyces nitens (C. Agardh) Kunze FBL 504

Rhizopus stolonifer var. stolonifer (Ehrenb.) Vuill. FBL 256

Stilbella sp. FBL 501

Trichoderma harzianum Rifai FBL 365

Umbelopsis nana (Linnem.) Arx FBL 77

Volutella sp. FBL 369 diameter $(\mathrm{mm}) \quad(\mathrm{mm})$

(g)

$\begin{array}{lcccc}64.0 \pm 3.6 & 26.7 \pm 10.4 & 0.094 \pm 0.004 & 4.39 \pm 0.17 \\ 55.0 \pm 5.0 & 8.3 \pm 1.5 & 0.027 \pm 0.005 & 4.50 \pm 0.17 \\ 35.0 \pm 0.0 & 8.7 \pm 15.0 & 0.025 \pm 0.004 & 3.72 \pm 0.23 \\ 58.0 \pm 7.6 & 3 \pm 5.2 & 0.011 \pm 0.001 & 4.69 \pm 0.55 \\ 72.0 \pm 7.2 & 73.3 \pm 5.8 & 0.136 \pm 0.009 & 1.53 \pm 0.07 \\ 16.0 \pm 1.7 & 0 \pm 0 & 0.036 \pm 0.059 & 5.36 \pm 0.32 \\ 21.0 \pm 1.7 & 0 \pm 0 & 0.004 \pm 0.002 & 5.93 \pm 0.45 \\ 11.0 \pm 1.7 & 0 \pm 0 & 0.004 \pm 0.002 & 6.93 \pm 0.23 \\ 27.3 \pm 2.5 & 4.0 \pm 3.6 & 0.044 \pm 0.010 & 4.33 \pm 0.16 \\ 24.3 \pm 0.6 & 6.0 \pm 0.0 & 0.025 \pm 0.005 & 4.43 \pm 0.41 \\ 45.0 \pm 5.0 & 10.7 \pm 0.6 & 0.013 \pm 0.000 & 4.62 \pm 0.26 \\ 21.3 \pm 5.5 & 16.7 \pm 0.6 & 0.019 \pm 0.002 & 4.26 \pm 0.49 \\ 25.0 \pm 5.0 & 4.0 \pm 3.6 & 0.008 \pm 0.001 & 6.18 \pm 0.37 \\ 29.0 \pm 1.7 & 5.7 \pm 5.1 & 0.015 \pm 0.004 & 4.54 \pm 0.29 \\ 29.0 \pm 3.6 & 4.7 \pm 4.0 & 0.011 \pm 0.001 & 5.06 \pm 0.17 \\ 24.0 \pm 2.0 & 6.7 \pm 2.5 & 0.010 \pm 0.000 & 5.07 \pm 1.02 \\ 30.0 \pm 3.6 & 11.7 \pm 2.9 & 0.028 \pm 0.005 & 4.30 \pm 0.18 \\ 41.7 \pm 2.9 & 0 \pm 0 & 0.019 \pm 0.002 & 4.78 \pm 0.29 \\ & & & \\ 24.0 \pm 1.0 & 5.0 \pm 1.7 & 0.010 \pm 0.001 & 5.16 \pm 0.29 \\ & & & \end{array}$

organic forms of $\mathrm{P}$ could be, in fact, of interest in agriculture, where slow release organo-mineral fertilisers could find a market.

The strains were reactivated and routinely maintained on malt extract agar (MEA, Difco, Sparks, MD, USA). Pikovskaya (PVK) agar with $5 \%$ of tricalcium phosphate $\left[\mathrm{Ca}_{3}\left(\mathrm{PO}_{4}\right)_{2}\right]$ (TCP) (Pikovskaya 1948; Nautiyal 1999) was employed to screen phosphate solubilising microorganisms by a plate assay method. Therefore, the only $\mathrm{P}$ source was represented by the insoluble TCP. The $\mathrm{pH}$ of the media, not adjusted, was $6.5 \pm 0.2$. For the experiments sterile cellophane membranes (Focus Packaging and Design Ltd, Louth, UK) were used according to Sayer and Gadd (1997) and to Ceci et al. (2015). The fungal strains were grown for at least 7 days on MEA at $25^{\circ} \mathrm{C}$ in the dark prior to experimental subculture. Inoculation was carried out by using $5 \mathrm{~mm}$ diameter cores of mycelium taken from actively growing margins of stock colonies by using a sterile cork borer. Fungal growth was evaluated by diametric extension and by the biomass yield (Vodnik et al. 
1998). After 7 days, fungal colonies were removed from the agar by peeling the biomass from the cellophane membranes using a sterile razor blade. Mycelia were ovendried at $100{ }^{\circ} \mathrm{C}$ until reaching constant weight for 2 days. After the biomass removal, the surface $\mathrm{pH}$ of the agar was measured at specific intervals across the diameter of the Petri dish using the $\mathrm{pH}$ portable meter for food and dairy HI 99161, fitted with a conical tip FC 202D pH electrode (Hanna Instruments, Woonsocket, RI, USA). The ability of different strains to solubilise phosphate was determined after 7 days of incubation at $25^{\circ} \mathrm{C}$ in the dark by employing two different indices. The solubilisation index (SI) was calculated according to Gudiño Gomezjurado et al. (2015). Moreover, a further index has been proposed and used in this research, taking account the measures of the diameter of the fungi, the diameter of the halo zone around the growing colonies and the average medium $\mathrm{pH}$. The solubilisation- $-\mathrm{pH}$ index $(\mathrm{SpHI})$ was calculated according to the following formula:

$\mathrm{SpHI}=\mathrm{SI} \times\left(\overline{\mathrm{pH}_{\mathrm{C}}}-\overline{\mathrm{pH}_{\mathrm{T}}}\right)$

where SI is the solubilisation index above-described, and $\mathrm{pH}_{\mathrm{C}}$ and $\mathrm{pH}_{\mathrm{T}}$ are the average values of $\mathrm{pH}$ at control (PVK without fungus) and test, respectively.

Among the species previously tested in PVK solid medium a subset was chosen to be studied in PVK liquid medium for further investigations in different cultural conditions (Table 3).

The solubilisation index (SI) (Gudiño Gomezjurado et al. 2015), used to evaluate the solubilisation potential of tested fungal strains, takes account of both the halo zone formation and the diametric extension. This index is based on parameters of fungal morphology and growth. While $\mathrm{SpHI}$ index, proposed in this research, integrates the previous parameters with the lowering of medium $\mathrm{pH}$ which is related to fungal metabolic activity. Hence, the SpHI is a more comprehensive index, which may help to better select P-solubilisers.

\section{Solubilisation test in PVK broth medium}

The experiments on PVK broth medium were carried out to evaluate the responses in these cultural conditions of the studied species and by performing observations on fungal mycelium and elemental analyses on biomass samples using SEM/EDS. In this way, it was possible to better investigate the biotransformation of TCP by fungi without the interferences of agar.

Solubilisation activity was carried out in $35 \mathrm{ml}$ PVK broth medium in $150 \mathrm{ml}$ sterile containers at $25^{\circ} \mathrm{C}$ in the dark. Inoculation was carried out as described above. The $\mathrm{pH}$ of the medium was not adjusted and was $6.4 \pm 0.0$. Fungi were grown floating on the surface of the liquid PVK by the means of a perforated plastic support, in order to prevent the contact with TCP precipitated at the bottom of the containers. The fungal mycelia were harvested from liquid PVK by filtration using filter paper (WhatmanRapida A Perfecte, Milan, Italy) and washing twice with distilled sterile water. Mycelia were oven-dried to estimate the dry weights. Fresh biomass subsamples and TCP were collected to be analysed by SEM/EDS before drying. The $\mathrm{pH}$ of liquid PVK was analysed for all tested fungi.

\section{Scanning electron microscopy (SEM)-energy- dispersive X-ray spectroscopy (EDS)}

The fresh biomass of nine fungal species was examined uncoated, after the static liquid experiments using a variable pressure SEM (EVO50, Carl-Zeiss Electron Microscopy Group) equipped with a detector for backscattered electrons (BSE). Chemical analysis was performed by means of EDS (INCA 250, Oxford). The SEM was fitted with a tungsten filament and operated at $20 \mathrm{keV}$, with an average working distance of $12.5 \mathrm{~mm}$, and with a chamber pressure between 30 and $150 \mathrm{~Pa}$, chosen according to the need for maintenance of fungal turgidity. The EDS analyses were calibrated using standards $\left(\mathrm{CaCO}_{3}, \mathrm{SiO}_{2}\right.$, Albite, $\mathrm{MgO}, \mathrm{Al}_{2} \mathrm{O}_{3}, \mathrm{GaP}, \mathrm{FeS}_{2}$, Wollastonite, MAD-10 Feldspar, $\mathrm{Ti}$ and $\mathrm{Fe}$ ), and the conventional ZAF correction (for atomic number $\mathrm{Z}$, absorption and fluorescence) was applied, integrated into the Oxford INCA 250 microanalysis package used (Burford et al. 2003).

In the SEM-EDS analysis, the fungal biomass which developed on the surface of the static cultures was sampled with plastic tweezers and deposited on aluminium stubs (12.5 mm, Agar Scientific) fitted by a sulphur free carbon adhesive (Agar Scientific). EDS spectra were acquired pointing at fungal mycelium and at the biogenic minerals eventually formed within the biomass. Two separate datasets were organised in order to obtain information on the elemental composition of the mycelium and the minerals that it concentrated and eventually precipitated.

\section{Statistical analysis}

One-way analysis of the variance (ANOVA) was firstly applied on diametric colony extension, biomass yield, halo zones diametric extension and $\mathrm{pH}$, and the significance of the differences was tested at $95 \%$ confidence. ANOVA was followed by stepwise multiple comparisons using the Newman-Keuls (SNK) method. Moreover, principal component analysis (PCA) was performed on these four variables. All the experiments were run in triplicate. ANOVA was also applied on the EDS measurements to evaluate the relationships between variables (e.g. elements, fungal strain, crystals) and the significance of the differences 
between samples. The variables were the 9 chemical elements analysed $(\mathrm{C}, \mathrm{O}, \mathrm{Na}, \mathrm{Ca}, \mathrm{Mg}, \mathrm{K}, \mathrm{Cl}, \mathrm{S}, \mathrm{P})$. In this case, the ANOVA model used was "unbalanced" because the number of observations within each category was not the same. ANOVA was followed by a post hoc analysis using Tukey, and Bonferroni correction procedure in determining the critical value for significance. Statistical analyses of the SEM-EDS chemical data were used to investigate if it was possible to discriminate between fungal routes of TCP dissolution and P uptake mechanisms. PCA was then applied to the SEM-EDS results to study and visualise the correlations among all the variables (Massart et al. 1998). The statistical package XLStat (Addinsoft 2007-Pro, Paris, France) was used for all the statistical processing.

\section{RESULTS}

\section{Solubilisation test in PVK agar medium}

All tested fungi were able to grow on PVK solid medium. $R$. stolonifer var. stolonifer and T. harzanium were the best performing fungi, showing the highest average diametric extension values and the highest overall growth rates of colonies (Table 1). ANOVA revealed that the growth extension for these fungi was significantly higher than all the other strains and control $(p<0.001)$. With regard to the diametric extension of the solubilisation halo zones, $R$. stolonifer var. stolonifer, A. niger and A. alternata resulted the best performing strains (Table 1). The halo zones formed by these strains were significantly larger than for all the other species. A. niger, R. stolonifer var. stolonifer and $H$. taiense showed the highest Solubilisation Index $(0.7>\mathrm{SI} \geq 1)$ (Table 2). A. niger, A. alternata, $P$. griseofulvum, $P$. marquandii, $R$. stolonifer var. stolonifer showed the highest biomass yields which were significantly higher than all the tested strains $(p<0.001)$ (Table 1). All fungi were able to lower the initial $\mathrm{pH}$ of $\mathrm{PVK}$ medium. A. niger and $R$. stolonifer var. stolonifer showed the lowest $\mathrm{pH}$ values, which were significantly different from those of the other tested strains $(p<0.01)$ (Table 1$)$. A. niger, R. stolonifer var. stolonifer, $H$. taiense and P. lilacinus showed the highest $\mathrm{SpHI}$ values $(\mathrm{SpHI}>1)$ (Table 2). This index was used to select the nine fungal strains among all to carry out experiments in liquid PVK.

The values of diametric extension (DIAM), $\mathrm{pH}$, diametric extension of solubilisation halo zones $(\mathrm{SH})$ and biomass yield (DW) varied consistently among the 30 strains. They showed some statistically significant correlations (Fig. 1) and some expected autocorrelations that, however, can be an expression of the underlying mechanisms in TCP solubilisation by fungi with different
Table 2 Solubility indexes calculated on the 30 fungal strains according to the variables reported in Table 1. The Solubilisation Index (SI) was calculated according to the ratio of the total diameter (colony + halo zone) and the colony diameter (El-Azouni 2008). The Solubility $\mathrm{pH}$ Index $(\mathrm{SpHI})$ is here proposed for the first time and respect to the other index also considers the average agar $\mathrm{pH}$ at the end of incubation

\begin{tabular}{|c|c|c|c|}
\hline Fungal strains & Acronyms & S.I. & $\mathrm{SpHI}$ \\
\hline Alternaria alternata FBL 508 & Alt1 & 0.42 & 0.87 \\
\hline Alternaria sp. FBL 507 & Alt2 & 0.15 & 0.30 \\
\hline Anamorphic fungus FBL 165 & Anm & 0.25 & 0.68 \\
\hline Arthrinium arundinis FBL 266 & Arth & 0.05 & 0.09 \\
\hline Aspergillus niger FBL 453 & Asp1 & 1.02 & 4.97 \\
\hline Aspergillus sp. FBL 253 & Asp2 & 0.00 & 0.00 \\
\hline Cadophora fastigiata FBL 557 & Cado & 0.00 & 0.00 \\
\hline Cladosporium sp. FBL 513 & Clad1 & 0.00 & 0.00 \\
\hline Cladosporium tenellum FBL 505 & Clad2 & 0.15 & 0.31 \\
\hline Engyodontium album FBL 458 & Engy & 0.25 & 0.51 \\
\hline Epicoccum nigrum FBL 181 & Epic & 0.24 & 0.44 \\
\hline Heterocephalum taiense FBL 249 & Hete & 0.78 & 1.73 \\
\hline Microdiplodia sp. FBL 512 & Micr & 0.16 & 0.05 \\
\hline Minimedusa polyspora 7 FBL 503 & Min1 & 0.20 & 0.38 \\
\hline Minimedusa polyspora 5b FBL 514 & $\operatorname{Min} 2$ & 0.19 & 0.26 \\
\hline Minimedusa polyspora 5a FBL 502 & Min3 & 0.28 & 0.39 \\
\hline Mortierella globalpina FBL 74 & Mort & 0.39 & 0.85 \\
\hline Myrothecium cinctum FBL 383 & Myr1 & 0.00 & 0.00 \\
\hline Myrothecium verrucaria FBL 385 & Myr2 & 0.21 & 0.27 \\
\hline Oidiodendron sp. FBL 319 & Oidi & 0.20 & 0.25 \\
\hline Paecilomyces lilacinus FBL 320 & Pae1 & 0.47 & 1.05 \\
\hline Paecilomyces marquandii FBL 321 & Pae2 & 0.34 & 0.54 \\
\hline Paecilomyces variotii FBL 213 & Pae3 & 0.00 & 0.00 \\
\hline Penicillium griseofulvum FBL 500 & Peni & 0.30 & 0.62 \\
\hline Phycomyces nitens FBL 504 & Phy & 0.08 & 0.17 \\
\hline Rhizopus stolonifer var. stolonifer FBL 256 & Rhiz & 1.00 & 2.87 \\
\hline Stilbella sp. FBL 501 & Stil & 0.13 & 0.10 \\
\hline Trichoderma harzianum FBL 365 & Tric & 0.02 & 0.03 \\
\hline Umbelopsis nana FBL 77 & $\mathrm{Umb}$ & 0.00 & 0.00 \\
\hline Volutella sp. FBL 369 & Volu & 0.59 & 0.83 \\
\hline
\end{tabular}

genotypes and phenotypes. In particular, positive correlation between diametrical extension and biomass yield $(R=0.522, p<0.001)$, positive correlation between diametrical extension and solubilisation halo zone $(R=0.632$, $p<0.001)$ and negative correlations between all the growth parameters (DW, SH and Diam) and the $\mathrm{pH}$ were observed. The strongest negative correlation was referred to $\mathrm{pH}$ and the solubilisation halo $(R=-0.648, p<0.001)$. In the PCA plot (Fig. 1) the first component (F1) accounted for the $69.29 \%$ of data variability while the second component accounted for the $12.31 \%$ of the variability. 

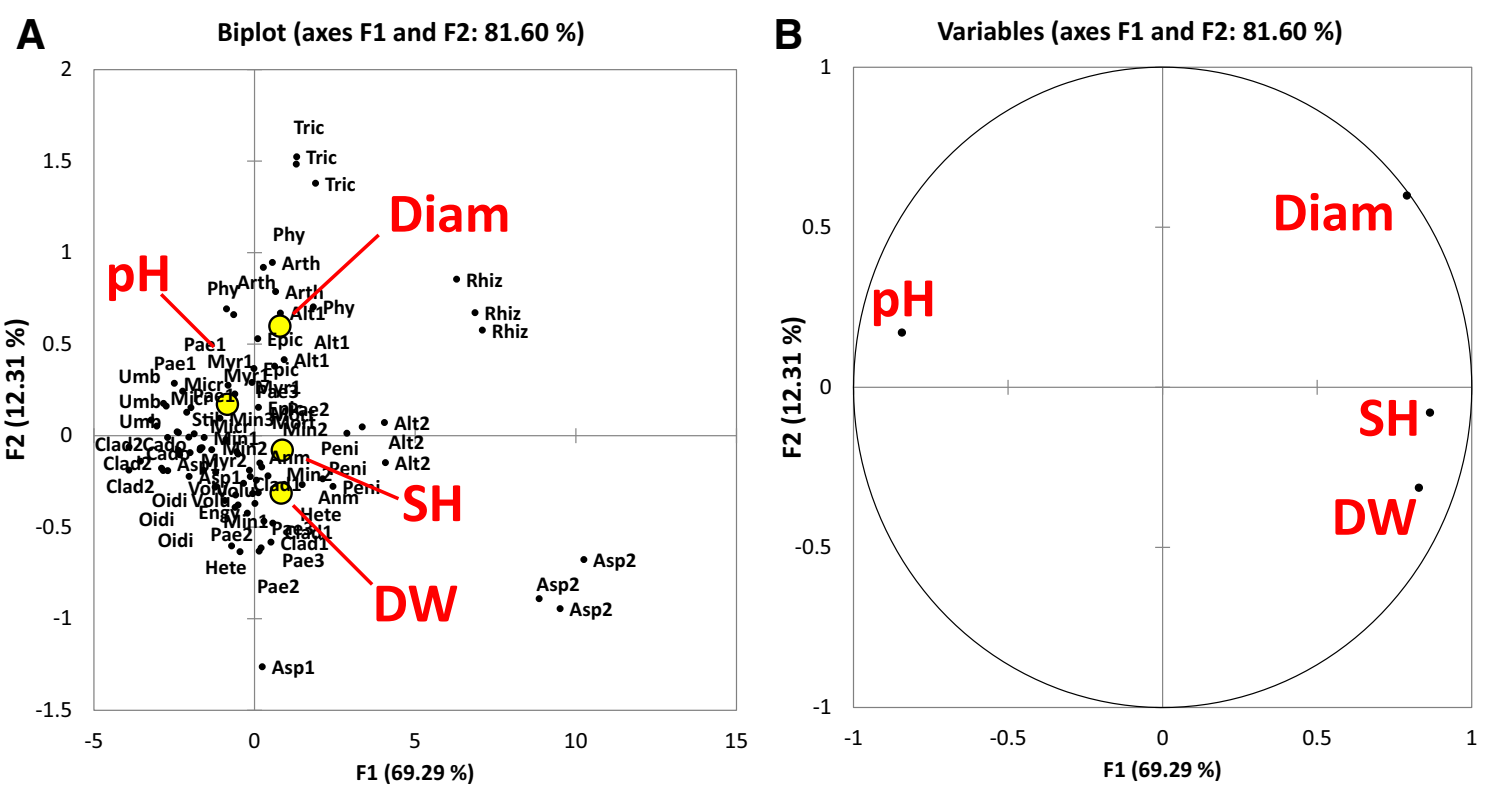

Fig. 1 Principal component analysis (Pearson). A Plot of the two principal components obtained from the data of diametric extension (DIAM), $\mathrm{pH}$, diametric extension of solubilisation halo zones $(\mathrm{SH})$ and biomass yield (DW). B Correlation plot between loadings and variables. Bartlett sphericity test for the first two components: the computed $p$ value is $>0.001$, lower than the significance level alpha $=0.05$, thus we accepted the hypothesis $\mathrm{Ha}$ (at least one of the correlations between the variables is significantly different from 0 ). The correlation between the variables is reported and discussed in the text

In the ordination space, the fungal species observations were mainly distributed in the centre of the plot, except a few outliers, such as Aspergillus sp. FBL 253, R. stolonifer var. stolonifer, Alternaria sp., C. tenellum, P. nitens, A. arundinis and T. harzianum (Fig. 1).

\section{Solubilisation test in PVK broth medium}

A. niger, $H$. taiense and $M$. globalpina showed the highest biomass yields, which were significantly higher than all tested strains $(p<0.001)$ (Table 3$)$. All fungi were able to lower the initial $\mathrm{pH}$ of PVK broth medium. A. niger, $P$. griseofulvum and $R$. stolonifer var. stolonifer showed the lowest $\mathrm{pH}$ values, which were significantly different from those of the other tested strains $(p<0.001)$ (Table 3$)$.

\section{Scanning electron microscopy (SEM)}

The fungus that accumulated more $\mathrm{P}$ in the biomass was $R$. stolonifer var. stolonifer (Table 4), followed by P. griseofulvum and A. niger. R. stolonifer var. stolonifer precipitated also secondary containing $\mathrm{P}$ minerals in its biomass.

Other fungi that promoted the accumulation of $\mathrm{P}$ containing minerals in the floating fungal biomass were $P$. nitens and H. taiense. R. stolonifer var. stolonifer was able also to store calcium $(\mathrm{Ca})$ both in its hyphae and in deposited biogenic minerals. Other species that were effective in absorbing $\mathrm{Ca}$ in the mycelium were $P$. nitens and $P$. griseofulvum. The precipitation of biogenic minerals
Table 3 The nine fungal strains selected among the 30 tested in solid culture to be essayed in static liquid experiments on Pikovskaya's medium containing 5\% insoluble tricalcium phosphate as only $\mathrm{P}$ source. The table reports the fungal biomass dry weights and the $\mathrm{pH}$ of the liquid medium at the end of the incubation. The values are reported as averages \pm Standard deviations from ten biological replicas

\begin{tabular}{llll}
\hline & Fungal strains & Dry weight $(\mathrm{g})$ & $\mathrm{pH}$ \\
\hline 1 & Mortierella globalpina & $0.285 \pm 0.013$ & $5.09 \pm 0.08$ \\
2 & Minimedusa polyspora & $0.019 \pm 0.001$ & $5.75 \pm 0.13$ \\
3 & $\begin{array}{c}\text { Rhizopus stolonifer } \text { var. } \\
\text { stolonifer }\end{array}$ & $0.195 \pm 0.011$ & $3.96 \pm 0.11$ \\
4 & Paecilomyces marquandii & $0.129 \pm 0.010$ & $5.60 \pm 0.27$ \\
5 & Phycomyces nitens & $0.013 \pm 0.005$ & $6.36 \pm 0.12$ \\
6 & Heterocephalum taiense & $0.322 \pm 0.014$ & $5.05 \pm 0.16$ \\
7 & Paecilomyces lilacinus & $0.182 \pm 0.025$ & $5.18 \pm 0.29$ \\
8 & Penicillium griseofulvum & $0.193 \pm 0.037$ & $3.39 \pm 0.11$ \\
9 & Aspergillus niger & $0.311 \pm 0.019$ & $2.04 \pm 0.18$ \\
\hline
\end{tabular}

based on Ca was massive in many species (Table 4). Biogenic minerals containing a high $\mathrm{Ca}$ concentration were produced in the fungal biomass by almost all the species and in particular by $P$. griseofulvum, M. polyspora, $R$. stolonifer var. stolonifer, and P. nitens (Fig. 2, Table 4).

Distinctive calcium oxalates crystals (Fig. 2), both in the bipyramidal form of $\mathrm{CaC}_{2} \mathrm{O}_{4}(2+\mathrm{X}) \cdot \mathrm{H}_{2} \mathrm{O}$ and in the monohydrate form $\mathrm{CaC}_{2} \mathrm{O}_{4} \cdot \mathrm{H}_{2} \mathrm{O}$ were observed in some of the fungal biomasses grown at the presence of TCP. 
Table 4 Phosphorus (P) and Calcium (Ca) average concentration (wt\%) in the fungal biomass floating on the surface of the static cultures (Fungal Biomass), and $\mathrm{P}$ and Ca content in the biogenic minerals found embedded in the same fungal biomasses (Biogenic minerals) in samples $1-9$, corresponding to as many fungal species. The data were obtained with energy-dispersive X-ray spectroscopy (EDS), from different areas of the fungal biomass as visualised with a variable pressure scanning electron microscope equipped with a backscattered electron detector, which permitted to distinguish between embedded minerals and fungal structures. Sample 7 did not show any biogenic mineral in the suspended mycelium. The numbering of the 9 species is the same used in the PCA plots of Fig. 3

\begin{tabular}{llllll}
\hline & & P biomass & P biogenic minerals & Ca biomass & Ca biogenic minerals \\
\hline 1 & M. globalpina & $1.1 \pm 0.2^{\mathrm{e}}$ & $1.6 \pm 0.1^{\mathrm{b}, \mathrm{c}}$ & $0.3 \pm 0.2^{\mathrm{d}}$ & $0.5 \pm 0.2^{\mathrm{c}}$ \\
2 & M. polyspora & $0.9 \pm 0.3^{\mathrm{e}}$ & $0.2 \pm 0.1^{\mathrm{c}}$ & $1.3 \pm 2.6^{\mathrm{d}}$ & $15.6 \pm 6.5^{\mathrm{a}}$ \\
3 & R. stolonifer var. stolonifer & $4.7 \pm 2.3^{\mathrm{a}}$ & $6.4 \pm 1.2^{\mathrm{a}}$ & $11 \pm 4.8^{\mathrm{a}}$ & $12.7 \pm 2.5^{\mathrm{a}, \mathrm{b}}$ \\
4 & P. marquandii & $1 \pm 0.5^{\mathrm{e}}$ & $2.4 \pm 1^{\mathrm{b}}$ & $1 \pm 0.9^{\mathrm{d}}$ & $3.8 \pm 2^{\mathrm{c}}$ \\
5 & P. nitens & $1.9 \pm 0.6^{\mathrm{c}, \mathrm{d}}$ & $3.4 \pm 2.7^{\mathrm{a}, \mathrm{b}}$ & $4.2 \pm 2.2^{\mathrm{c}}$ & $10.3 \pm 7.1^{\mathrm{b}}$ \\
6 & H. taiense & $1 \pm 0.4^{\mathrm{e}}$ & $4 \pm 1.7^{\mathrm{a}, \mathrm{b}}$ & $0.8 \pm 0.6^{\mathrm{d}}$ & $7.1 \pm 4.3^{\mathrm{b}, \mathrm{c}}$ \\
7 & P. lilacinus & $1.4 \pm 0.3^{\mathrm{d}, \mathrm{e}}$ & $\mathrm{nd}$ & $0 \pm 0^{\mathrm{d}}$ & $\mathrm{nd}$ \\
8 & P. griseofulvum & $2.4 \pm 1.4^{\mathrm{b}, \mathrm{c}}$ & $2.3 \pm 1.5^{\mathrm{b}}$ & $6.9 \pm 7.3^{\mathrm{b}}$ & $19.4 \pm 9.8^{\mathrm{a}}$ \\
9 & A. niger & $2.7 \pm 1.3^{\mathrm{b}}$ & $2.1 \pm 1.1^{\mathrm{b}, \mathrm{c}}$ & $0.9 \pm 1.3^{\mathrm{d}}$ & $6.3 \pm 2.4^{\mathrm{b}, \mathrm{c}}$ \\
\hline
\end{tabular}

Different letters (from "a" to "e") indicate significant differences (ANOVA post hoc analysis, $p<0.05$ ) between the species for the investigated parameters. $n d$ indicates no values could be determined
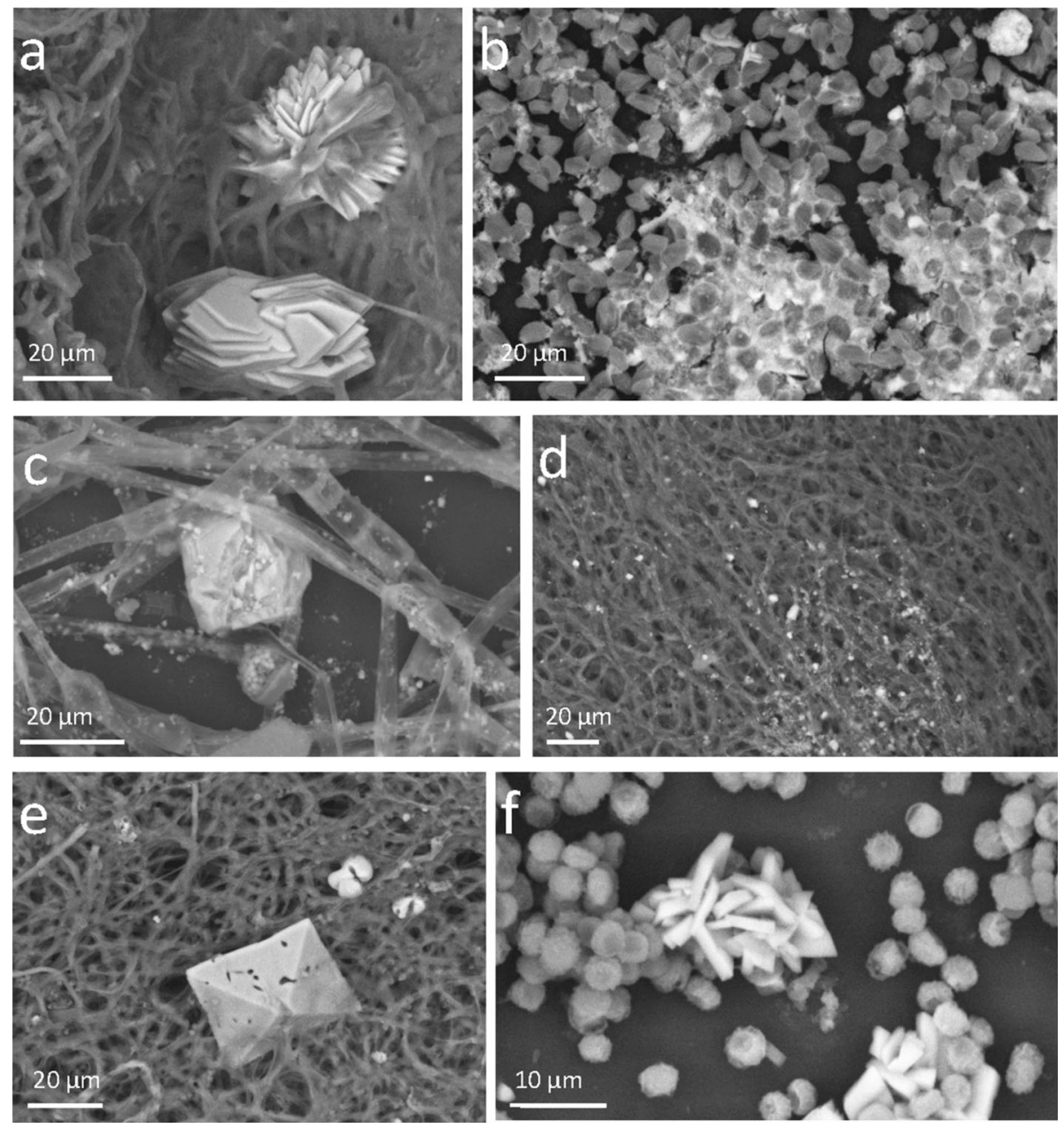

Fig. 2 VP-SEM-BSD images of fungal biomass with embedded secondary biogenic crystals or mineral precipitates. The images were obtained observing not fixed or metallised fresh fungal material at a pressure of about $60 \mathrm{~Pa}$. The objects made of elements with a higher atomic number appear lighter than organic ones. Backscattered electrons, in fact, return chemical images of what scanned. a Minimedusa polyspora, b Rhizopus stolonifer var. stolonifer, c Phycomyces nitens, $\mathbf{d}$ Heterocephalum taiense, e Penicillium griseofulvum, $\mathbf{f}$ Aspergillus niger 

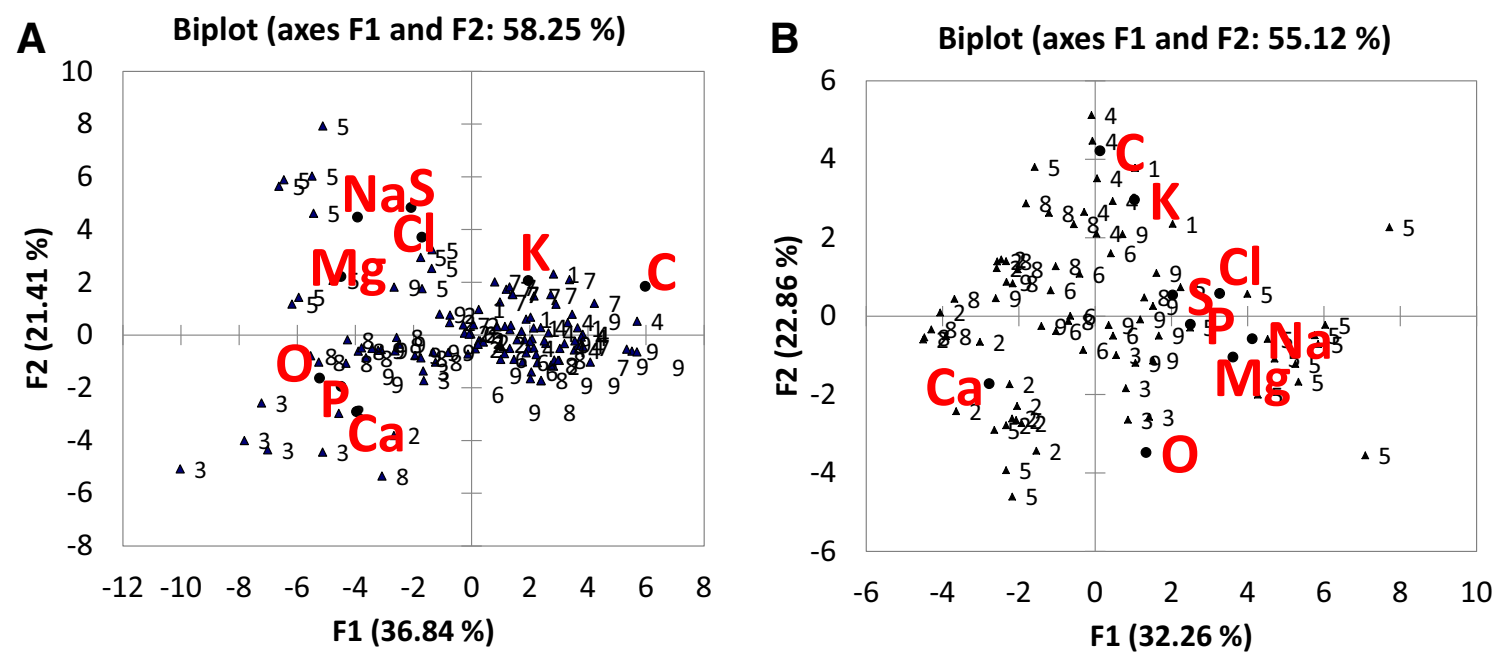

Fig. 3 Principal component analysis (Pearson). A Plot of the two principal components obtained from the elemental composition dataset (EDS measurements) of fungal biomasses; B Plot of the two principal components obtained from the elemental composition dataset (EDS measurements) of crystals and mineral precipitates embedded in fungal biomasses

Oxalate crystals exhibited a variety of crystalline forms (bipyramidal, plate-like, druses, rhombohedral, etc.).

The PCA plots (Fig. 3) showed that in fungal mycelium (Plot A) and in the biogenic crystals and mineral precipitates embedded in the fungal biomasses, the correlation between microelements was different. In particular, the Plot A (elemental composition of fungal biomasses) showed a correlation between the uptake of $\mathrm{P}$ and $\mathrm{Ca}$, with the $\mathrm{X}$ axis representing the concentration of elements (decreasing from left to right). While in the Plot B (elemental composition of crystals and mineral precipitates embedded in fungal biomasses) $\mathrm{P}$ and $\mathrm{Ca}$ were inversely correlated. All the elements in the plot, except $\mathrm{Ca}$ and $\mathrm{P}$, came from the liquid media (PVK), while $\mathrm{Ca}$ and $\mathrm{P}$ resulted from the solubilisation of the added TCP.

In the Plot A, the species 3, 8 and 5 ( $R$. stolonifer var. stolonifer, $P$. nitens and $P$. griseofulvum) were positively correlated to $\mathrm{Ca}$ and P. In Plot B the species correlated with $\mathrm{Ca}$ were those exhibiting calcium oxalate crystals $(M$. polyspora, A. niger, $P$. griseofulvum).

\section{DISCUSSION}

The results of our study showed TCP solubilisation by 30 fungal strains with different metabolisms and life-styles. The correlation between the extension of solubilisation halo and the $\mathrm{pH}$ values in the solid medium experiment suggested that one of the main mechanisms of TCP solubilisation may be the production and release of organic acids by fungi. This is corroborated by other studies that showed how fungal solubilisation of $\mathrm{P}$ compounds in liquid cultures is positively correlated to the amount of released acidic compounds (Gupta et al. 1994; Rosling et al. 2007). Nevertheless, some other mechanisms, such as enzymes production could have played a substantial role in the mechanisms put at place by the tested fungal strains to uptake P. The main mechanisms that fungi use to acidify their microenvironment can vary due to both the strains and the kind of substrate. These mechanisms could represent the main discriminant in the choice of the best strains to be used as a solubilisation aid in agricultural soils. In fact, fungi may induce TCP weathering also through cation biosorption to exchange sites in the cell wall (Marschner et al. 1998) and modulate uptake and availability of $\mathrm{P}$ by storing it in new mineral forms that precipitate in the mycelium (Rosling et al. 2007). The slow release of soluble $P$ could represent a remedy for those agricultural soils that genetically promote $\mathrm{P}$ immobilisation, and render the use of phosphate fertilisers useless. According to Burford et al. (2003) fungi solubilise minerals, including phosphate rocks, with active secretion of organic acids, proton efflux out the plasma membrane, formation of carbonic acid in the media as a result of respiratory $\mathrm{CO}_{2}$ production. Fungi that produce a clear zone under their growing colony in a solid medium that contains insoluble calcium phosphate are phosphorus-solubilising organisms (Whitelaw 2000). According to this definition 6 strains out of the 30 tested did not result as P solubilisers. These six strains, however, did grow in the solid medium, despite the absence of available P. These species could have recycled and used the little amounts of $\mathrm{P}$ available from the same inoculum, and this could have sustained the growth of the mycelium for a short time. On the other side, it is not possible to exclude that these strains could have used some of the insoluble P present in TCP with unidentified mechanisms 
which granted them a P supply, although without visible effects in terms of minerals leaching. M. cinctum, for instance, produced a mycelium with an average diameter of $41.7 \pm 2.9 \mathrm{~mm}$, and a dry weight $(0.019 \pm 0.002 \mathrm{~g})$ far higher than other species that conversely showed important solubilisation halos. Moreover, although M. cinctum showed some degree of acidification ability $(\mathrm{pH}$ $4.78 \pm 0.29)$ it did not produce a solubilisation halo, highlighting that the link between halo formation on TCP and solubilisation ability a non-univocal one. It is possible that the kind of acid produced defines most the dissolution pattern of TCP in the media, despite the real need for $\mathrm{P}$ of the growing fungus. According to Rosling et al. (2007) in Mucorales exudates predominates the oxalic acid, which can induce both TCP and fluorapatite dissolution at high rates. Besides, some Ascomycetes induce P-minerals dissolution by lowering the $\mathrm{pH}$ of the media without producing significant amounts of low molecular weight organic acids (Rosling et al. 2007). The hypothesis formulated by Rosling et al. (2007), and somehow confirmed by our results, is that while low molecular weight organic acids are strong dissolution agents, they do not appear to be produced by all fungi in response to P-limiting growth conditions, because other equally efficient but not entirely revealed and explained mechanisms allow fungi to obtain $\mathrm{P}$ from limiting environments. It follows that the in vitroscreening of fungi performed by measuring only the solubilisation halo and the $\mathrm{pH}$ is inefficient in strains selection.

In our experiment, the more diffusible compounds, capable of lowering the $\mathrm{pH}$ of the medium, were produced by the fungi, and more TCP was solubilised under the mycelium. However, although there was this correlation, the value of $\mathrm{R}$ suggested that not for all species the mechanism was so straightforward, and that there was a gradient that placed some species in a different position. This could be seen in the PCA plot of Fig. 1 where the first component (F1) could be interpreted as the growth of the fungi, while the second component, was mostly associated to $\mathrm{pH}$, indicating that these two fungal characteristics (fungal growth and lowering of $\mathrm{pH}$ ) occurred independently.

The SpHI index, proposed in this research, integrated the halo zone formation and the diametric extension used in the solubilisation index (SI) (Gudiño Gomezjurado et al. 2015) with the lowering of medium $\mathrm{pH}$, which is related to fungal metabolic activity, resulting in a more comprehensive and effective index for P-solubilisers selection.

Out of the nine species we tested more deeply, actually only four resulted phosphate solubilisers. The species $A$. niger, $P$. lilacinus, $P$. marquandii and $P$. griseofulvum showed a negative correlation between medium $\mathrm{pH}$ and solubilisation of $\mathrm{P}$, according to other authors (Cerezine et al. 1988; Reddy et al. 2002; Wakelin et al. 2004; Maurya and Kumar. 2006; Hernández-Leal et al. 2011; Qiu and Lian 2012; Posada et al. 2013). For the genus Mortierella, P-solubilisation has been already described (Osorio and Habte 2001) but for the species M. globalpina a remarkable efficiency of insoluble phosphate solubilisation, coinciding with decrease in medium $\mathrm{pH}$, has been showed for the first time.

The current study also showed that each of the nine fungal species used in the liquid media test, performed differently in terms of $\mathrm{P}$ uptake in the biomass and ability to precipitate secondary minerals in the mycelium. $R$. stolonifer var. stolonifer, $P$. marquandii, $P$. nitens precipitated $\mathrm{P}$ minerals in association with fungal mycelia. Biologically induced precipitation of hydroxyapatite has been demonstrated by Rosling et al. (2007) in Mucorales.

The multivariate output of EDS data (Fig. 3, plots A and B) showed that in fungal biomasses there was a correlation between the uptake of $\mathrm{P}$ and $\mathrm{Ca}$ while in mineral precipitates $\mathrm{P}$ and $\mathrm{Ca}$ were inversely correlated and $\mathrm{Ca}$ was released or taken up independently of $\mathrm{P}$.

The presence of calcium oxalate crystals associated with mycelia was observed in some of the tested fungi. Distinct crystals were, in fact, documented mainly in M. polyspora, A. niger, and $P$. griseofulvum. The production of oxalates by fungi during apatite or TCP solubilisation was reported to be a massive mechanisms of passive weathering, namely a release of acidic compounds in the media regardless of the fungal needs of elements for growth (Rosling et al. 2007; Pinzari et al. 2013). Interestingly in some fungi, Ca and $\mathrm{P}$ supplementation significantly affected the amount of calcium oxalate formed (Shinners and Tewari 1997; Tuason and Arocena 2009). In the fungus Piloderma fallax (Lib.) Stalpers more calcium oxalate was formed at high $\mathrm{P}$ levels, with a strong positive linear relationship between $\mathrm{Ca}$ level and calcium oxalate but only under conditions of $\mathrm{P}$ limitation (Tuason and Arocena 2009). The in vitro testing of fungal strains clearly does not include some important variables that come into play under natural conditions. Some species of fungi, highly performing in vitro, may have a different behaviour in natural situations. Their potential to colonise mineral surfaces and their geoactive properties need to be verified in conditions closer to real situations.

\section{CONCLUSIONS}

In this study, we described an optimisation of the steps and methods for evaluating the tricalcium phosphate solubilising strength of fungi. In particular, the chemical data, obtained analysing fungal mycelia with SEM-EDS technique, were used to discriminate between fungal routes of TCP dissolution and P uptake mechanisms. 
The solubilisation halo and the lowering of the $\mathrm{pH}$, taken individually, represented weak indicators of the real fungal potential to make $\mathrm{P}$ bioavailable to plants in soil. The results of our study showed that saprotrophic fungi can modulate uptake and availability of $\mathrm{P}$ by different mechanisms. In particular, they can store $\mathrm{P}$ in new mineral forms that precipitate in their mycelium and assimilate $\mathrm{P}$ in organic forms that could be released after the death of the same fungus, as well.

The wide and varied $\mathrm{P}$ storage and release strategies of fungi could be exploited to overcome $\mathrm{P}$ limitation in agricultural soils, and reduce the need for phosphate fertilisers. In fact, the uptake of $\mathrm{P}$ in the mycelium both as organic forms and as secondary P-bearing biogenic minerals could provide to soil a slow-release source of $\mathrm{P}$, that could be controlled by the requirements of plants roots and the community of soil decomposers.

Acknowledgements Financial assistance for this study and the related research project titled-Fungal solubilisation of phosphates for optimisation of $\mathrm{P}$ availability to improve plant nutrition (No. C26A153LY4) was provided by Sapienza University of Rome.

Author contributions Authors AC, FP, FR equally contributed to the experiments and the evaluation and analysis of data. In particular $\mathrm{AC}$ and FR performed the solubilisation tests while FP performed the SEM-EDS analysis. AMP and OM equally contributed to the design of the experiment, the choice of the methods, the interpretation of results. All the authors contributed to drafting the article and revising it critically for intellectual content.

Open Access This article is distributed under the terms of the Creative Commons Attribution 4.0 International License (http:// creativecommons.org/licenses/by/4.0/), which permits unrestricted use, distribution, and reproduction in any medium, provided you give appropriate credit to the original author(s) and the source, provide a link to the Creative Commons license, and indicate if changes were made.

\section{REFERENCES}

Bojinova, D., R. Velkova, and R. Ivanova. 2008. Solubilization of Morocco phosphorite by Aspergillus niger. Bioresource Technology 99: 7348-7353.

Bolan, N.S. 1991. A critical review on the role of mycorrhizal fungi in the uptake of phosphorus by plants. Plant and Soil 134: 189-207.

Burford, E.P., M. Fomina, and G.M. Gadd. 2003. Fungal involvement in bioweathering and biotransformation of rocks and minerals. Mineralogical Magazine 67: 1127-1155.

Burford, E.P., S. Hillier, and G.M. Gadd. 2006. Biomineralization of fungal hyphae with calcite $\left(\mathrm{CaCO}_{3}\right)$ and calcium oxalate monoand dihydrate in carboniferous limestone microcosms. Geomicrobiology Journal 23: 599-611.

Carvajal-Muñoz, J.S., and C.E. Carmona-Garcia. 2012. Benefits and limitations of biofertilization in agricultural practices. Livestock Research for Rural Development 24: 1-8.

Ceci, A., Y.J. Rhee, M. Kierans, S. Hillier, H. Pendlowski, N. Gray, A.M. Persiani, and G.M. Gadd. 2015. Transformation of vanadinite $\left[\mathrm{Pb}_{5}\left(\mathrm{VO}_{4}\right)_{3} \mathrm{Cl}\right]$ by fungi. Environmental Microbiology 17: 2018-2034.

Cerezine, P.C., E. Nahas, and D.A. Banzatto. 1988. Soluble phosphate accumulation by Aspergillus niger from fluorapatite. Applied Microbiology and Biotechnology 29: 501-505.

Cordell, D., J.O. Drangert, and S. White. 2009. The story of phosphorus: Global food security and food for thought. Global Environmental Change 19: 292-305.

El-Azouni, I.M. 2008. Effect of phosphate solubilizing fungi on growth and nutrient uptake of soybean (Glycine max L.) plants. Journal of Applied Sciences Research 4: 592-598.

Fomina, M., E.P. Burford, and G.M. Gadd. 2005. Fungal dissolution and transformation of minerals: Significance for nutrient and metal mobility. In Fungi in Biogeochemical Cycles, ed. G.M. Gadd, 236-266. Cambridge: Cambridge University Press.

Food and Agriculture Organization of the United Nations (FAO). 2015. World Fertilizer Trends and Outlook to 2018. Rome: Food and Agriculture Organization of the United Nations.

Gudiño Gomezjurado, M.E., L.M. de Abreu, L.M. Marra, L.H. Pfenning, and F.M. de S. Moreira. 2015. Phosphate solubilization by several genera of saprophytic fungi and its influence on corn and cowpea growth. Journal of Plant Nutrition 38: 675-686. https://doi.org/10.1080/01904167.2014.934480.

Gunther, F. 2005. A solution to the heap problem: the doubly balanced agriculture: Integration with population. https://www. holon.se/folke/kurs/Distans/Ekofys/Recirk/Eng/balanced.shtml.

Gupta, R.R., R. Singal, A. Shanker, R.C. Kuhad, and R.K. Saxena. 1994. A modified plate assay for screening phosphate solubilizing microorganisms. The Journal of General and Applied Microbiology 40: 255-260.

Halder, A.K., A.K. Mishra, P. Bhattacharyya, and P.K. Chakrabartty. 1990. Solubilization of rock phosphate by Rhizobium and Bradyrhizobium. The Journal of General and Applied Microbiology 36: 81-92.

Hernández-Leal, T., G. Carrión, and G. Heredia. 2011. In vitro phosphate solubilization by a strain of Paecilomyces lilacinus (Thom) Samson. Agrociencia 45: 881-892.

Jain, R., J. Saxena, and V. Sharma. 2012. Solubilization of inorganic phosphates by Aspergillus awamori S19 isolated from rhizosphere soil of a semi-arid region. Annals of Microbiology 62: 725-735.

Kucey, R.M.N. 1983. Phosphate solubilizing bacteria and fungi in various cultivated and virgin Alberta soils. Canadian Journal of Soil Science 63: 671-678.

Malusà, E., F. Pinzari, and L. Canfora. 2016. Efficacy of biofertilizers: challenges to improve crop production. In Microbial Inoculants in Sustainable Agricultural Productivity: Vol. 2: Functional Applications, ed. D.P. Singh, H.B. Singh, and R. Prabha, 17-40. New Delhi, India: Springer.

Marschner, P., G. Jentschke, and D.L. Godbold. 1998. Cation exchange capacity and lead sorption in ectomycorrhizal fungi. Plant and Soil 205: 93-98.

Massart, D.L., B.G.M. Vandeginste, L.M.C. Buydens, S. de Jong, P.J. Lewi, and J.S. Verbeke. 1998. Handbook of Chemometrics and Qualimetrics. Part B. Amsterdam: Elsevier Science.

Maurya, B.R., and A. Kumar. 2006. Comparative performance of Aspergillus niger isolates of different habitats on solubilisation of tricalcium phosphate in broth and their impact on yield attributes of wheat (Triticum aestivum L.). International Journal Of Agricultural Sciences 2: 581-583.

Nautiyal, C.S. 1999. An efficient microbiological growth medium for screening phosphate solubilizing microorganisms. FEMS Microbiology Letters 170: 265-270.

Oehl, F., E. Sieverding, P. Mäder, D. Dubois, K. Ineichen, T. Boller, and A. Wiemken. 2004. Impact of long-term conventional and 
organic farming on the diversity of arbuscular mycorrhizal fungi. Oecologia 138: 574-583.

Osorio, N.W., and M. Habte. 2001. Synergistic influence of an arbuscular mycorrhizal fungus and a $\mathrm{P}$ solubilizing fungus on growth and P uptake of Leucaena leucocephala in an Oxisol. Arid Land Research and Management 15: 263-274.

Owen, D., A.P. Williams, G.W. Griffith, and P.J.A. Withers. 2015. Use of commercial bio-inoculants to increase agricultural production through improved phosphorous acquisition. Applied Soil Ecology 86: 41-54.

Persiani, A.M., and O. Maggi. 1986. A new species of Heterocephalum from ivory coast soil. Transactions of the British Mycological Society 87: 631-635. https://doi.org/10.1016/ S0007-1536(86)80104-8.

Pikovskaya, R.I. 1948. Mobilization of phosphorus in soil in connection with vital activity of some microbial species. Mikrobiologiya 17: 362-370.

Pinzari, F., P. Colaizzi, O. Maggi, A.M. Persiani, R. Schütz, and I. Rabin. 2012. Fungal bioleaching of mineral components in a twentieth-century illuminated parchment. Analytical and Bioanalytical Chemistry 402: 1541-1550.

Pinzari, F., J. Tate, M. Bicchieri, Y.J. Rhee, and G.M. Gadd. 2013. Biodegradation of ivory (natural apatite): Possible involvement of fungal activity in biodeterioration of the Lewis Chessmen. Environmental Microbiology 15: 1050-1062.

Pinzari, F., M. Reverberi, G. Piñar, O. Maggi, and A.M. Persiani. 2014. Metabolic profiling of Minimedusa polyspora (Hotson) Weresub \& P.M. LeClair, a cellulolytic fungus isolated from Mediterranean maquis, in southern Italy. Plant Biosystems 148: 333-341.

Posada, R.H., G. Heredia-Abarca, E. Sieverding, and M. Sánchez de Prager. 2013. Solubilization of iron and calcium phosphates by soil fungi isolated from coffee plantations. Archives of Agronomy and Soil Science 59: 185-196.

Pradhan, N., and L.B. Sukla. 2006. Solubilization of inorganic phosphates by fungi isolated from agriculture soil. African Journal of Biotechnology 5: 850-854.

Qiu, S., and B. Lian. 2012. Weathering of phosphorus-bearing mineral powder and calcium phosphate by Aspergillus niger. Chinese Journal of Geochemistry 31: 390-397.

Reddy, M.S., S. Kumar, K. Babita, and M.S. Reddy. 2002. Biosolubilization of poorly soluble rock phosphates by Aspergillus tubingensis and Aspergillus niger. Bioresource Technology 84: 187-189.

Rosling, A., K.B. Suttle, E. Johansson, P.A.W. Van Hees, and J.F. Banfield. 2007. Phosphorous availability influences the dissolution of apatite by soil fungi. Geobiology 5: 265-280.

Rouached, H. 2016. Phosphorus in agriculture: Need for efficient use and re-use. Journal of Crop Research and Fertilizers 1: 1-2.

Saxena, J., and A. Jha. 2014. Impact of a phosphate solubilizing bacterium and an arbuscular mycorrhizal fungus (Glomus etunicatum) on growth, yield and $\mathrm{P}$ concentration in wheat plants. CLEAN-Soil, Air, Water 42: 1248-1252. https://doi.org/ $10.1002 /$ clen.201300492.

Sayer, J.A., and G.M. Gadd. 1997. Solubilization and transformation of insoluble inorganic metal compounds to insoluble metal oxalates by Aspergillus niger. Mycological Research 101: 653-661.

Shinners, T.C., and J.P. Tewari. 1997. Diversity in crystal production by some bird's nest fungi (Nidulariaceae) in culture. Canadian Journal of Chemistry 75: 850-856.

Tuason, M.M.S., and J.M. Arocena. 2009. Calcium oxalate biomineralization by Piloderma fallax in response to various levels of calcium and phosphorus. Applied and Environmental Microbiology 75: 7079-7085.
Vassilev, N., M. Vassileva, and I. Nikolaeva. 2006. Simultaneous P-solubilizing and biocontrol activity of microorganisms: potentials and future trends. Applied Microbiology and Biotechnology 71: 137-144. https://doi.org/10.1007/s00253-006-0380-z.

Vodnik, D., A.R. Byrne, and N. Gogala. 1998. The uptake and transport of lead in some ectomycorrhizal fungi in culture. Mycological Research 102: 953-958.

Wakelin, S.A., R.A. Warren, P.R. Harvey, and M.H. Ryder. 2004. Phosphate solubilization by Penicillium spp. closely associated with wheat roots. Biology and Fertility of Soils 40: 36-43.

Whitelaw, M.A. 2000. Growth promotion of plants inoculated with phosphate-solubilizing fungi. Advances in Agronomy 69: 99-151.

\section{AUTHOR BIOGRAPHIES}

Andrea Ceci is a postdoctoral fellow at the Sapienza University of Rome. His research interests include applied mycology, soil microbiology, geomicrobiology, ecology, environmental monitoring and bioremediation.

Address: Dipartimento di Biologia Ambientale, Sapienza Università di Roma, Piazzale Aldo Moro 5, 00185 Rome, Italy.

e-mail: andrea.ceci@uniroma1.it

Flavia Pinzari is a Researcher at the Italian Council for Agricultural Research and Economics (CREA). Her research interests are currently focused on soil microbiology, geomicrobiology, applied mycology and scanning electron microscopy applications in soil sciences.

Address: Consiglio per la ricerca in agricoltura e l'analisi dell'economia agraria. Centro di ricerca Agricoltura e Ambiente (CREA-AA), Via della Navicella 2-4, 00185 Rome, Italy.

e-mail: flavia.pinzari@crea.gov.it

Fabiana Russo is a PhD student at the Sapienza University of Rome. Her research interests include ecotoxicology, applied mycology, environmental monitoring and bioremediation.

Address: Dipartimento di Biologia Ambientale, Sapienza Università di Roma, Piazzale Aldo Moro 5, 00185 Rome, Italy.

e-mail: fabiana.russo@uniroma1.it

Oriana Maggi since June 30, 1981 joined as Assistant Professor at the Sapienza University of Rome, Department of Environmental Biology. She carries out teaching and research at this Department. She deals with various issues with respect to fungi: Mycology studies in natural ecosystems, cultivated and under stress, with interest in Ecology of microfungi in soil and litter; taxonomy and systematics of Eumicota, with description of new fungal taxa, their ultrastructural morphology and molecular investigations; investigations on environmental Mycology with evaluation of degradation of works of art and after restoration of the checks; investigations on the quality of air, surface and air conditioning systems, to verify the presence of human pathogenic microfungi.

Address: Dipartimento di Biologia Ambientale, Sapienza Università di Roma, Piazzale Aldo Moro 5, 00185 Rome, Italy.

e-mail: oriana.maggi@uniroma1.it

Anna Maria Persiani $(\bowtie)$ is an Associate Professor at the Sapienza University of Rome. Her research interests include taxonomic and functional biodiversity of soil fungi, fungal ecology, fungi and bioremediation, and environmental monitoring through fungi as bioindicators.

Address: Dipartimento di Biologia Ambientale, Sapienza Università di Roma, Piazzale Aldo Moro 5, 00185 Rome, Italy.

e-mail: annamaria.persiani@uniroma1.it 